\title{
Laboreal
}

Volume $2 \mathrm{~N}^{\circ} 2$ | 2006

Varia

\section{Saúde no trabalho e discrição das relações sociais}

Salud en el trabajo y discreción de las relaciones sociales

Santé au travail et discrétion des rapports sociaux

Health at work and discretion in social relations

\section{Carla Barros-Duarte e Marianne Lacomblez}

\section{(2) OpenEdition}

\section{Journals}

\section{Edição electrónica}

URL: http://journals.openedition.org/laboreal/13453

DOI: 10.4000/laboreal.13453

ISSN: 1646-5237

\section{Editora}

Universidade do Porto

\section{Refêrencia eletrónica}

Carla Barros-Duarte e Marianne Lacomblez, « Saúde no trabalho e discrição das relações sociais », Laboreal [Online], Volume $2 \mathrm{~N}^{\circ} 2$ | 2006, posto online no dia 01 dezembro 2006, consultado o 11 outubro 2019. URL : http://journals.openedition.org/laboreal/13453; DOI : 10.4000/laboreal.13453

Este documento foi criado de forma automática no dia 11 outubro 2019.

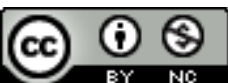

Laboreal está licenciado com uma Licença Creative Commons - Atribuição-NãoComercial 4.0 Internacional. 


\title{
Saúde no trabalho e discrição das relações sociais
}

\author{
Salud en el trabajo y discreción de las relaciones sociales \\ Santé au travail et discrétion des rapports sociaux \\ Health at work and discretion in social relations
}

Carla Barros-Duarte e Marianne Lacomblez

\section{REFERÊNCIA}

Artigo original : Barros Duarte, C. \& Lacomblez, M. (2006). Santé au travail et discrétion des rapports sociaux. PISTES, 8, 2, http://www.pistes.uqam.ca/v8n2/articles/

v8n2a2.htm

1 Este artigo retoma as principais ideias da tese de doutoramento em psicologia de Carla Barros Duarte (ver referência na bibliografia), complementado com dados mais recentes. $\mathrm{O}$ artigo foi redigido em conjunto pela autora e por Marianne Lacomblez, orientadora da tese.

2 Nos últimos quinze anos, em Portugal, tal como na maioria dos países da União Europeia, desenvolveram-se vários estudos no domínio da saúde no trabalho que conduziram a mudanças significativas ao nível das decisões e orientações políticas, seguidas pela produção de legislação específica e, também, pela criação de organismos orientados para um outro acompanhamento da segurança e saúde no trabalho. De facto, numerosos estudos científicos desenvolvidos nesta área (entre outros: DaubasLetourneux \& Thébaud-Mony, 2002; Derriennic, Touranchet \& Volkoff, 1996; Lacomblez, 2000 ; Marquié, Paumès \& Volkoff, 1995; Teiger, 1989) têm vindo a demonstrar a influência do trabalho nas evoluções da saúde.

3 Em Portugal assistimos ainda a poucas mudanças na concretização dos princípios gerais das políticas definidas em matéria de preservação da saúde no trabalho. Esta situação é particularmente preocupante nos sectores de produção ditos "tradicionais", nos quais a 
necessidade de reconversão é tida como evidente, e para as categorias de trabalhadores ditos de "baixo nível de qualificação", cuja economia nacional pouco se glorifica : tudo se desenrola como se fosse incontestável que as mudanças previstas ao longo dos anos eliminariam naturalmente os riscos profissionais enraizados no passado do país.

4 Por outro lado, a persistência em não integrar as especificidades da vida de trabalho na abordagem à saúde, reforça uma lógica que tende a manter na periferia as preocupações relativas aos efeitos constrangedores do trabalho sobre o bem-estar e as acções susceptíveis de os diminuir.

5 Na verdade, as relações entre a deterioração da saúde e o trabalho revestem-se de uma grande complexidade; na maior parte das vezes "não são nem unívocas nem instantâneas" (Gollac \& Volkoff, 2000, p. 23, tradução livre): constroem-se num conjunto de estados de saúde que, embora não sejam considerados patológicos, constituem sinais reveladores de sofrimento (Marquié, 1999), estabelecendo-se relações múltiplas e recíprocas pouco compatíveis com os diagnósticos tradicionais.

6 Também é certo que o próprio conceito de " saúde », habitualmente privilegiado, revela uma abordagem reducionista, unicamente associado à ausência de doença, não tendo, pois, em consideração as interaç̧ões entre as dimensões física, psicológica e social já reconhecidas pela OMS em 1946, e mais recentemente sublinhadas pelo Comité Misto da OIT/OMS (INRS, 1996).

7 Neste sentido, compreende-se que, face a uma lógica global pouco orientada para a explicitação dos riscos do trabalho, os trabalhadores acabem por não falar espontaneamente sobre as condições nas quais exercem a sua actividade profissional o contexto das relações sociais estabelecidas no seio da empresa reforçando-os, frequentemente, a ocultarem os efeitos do trabalho na sua saúde.

8 Mesmo que, actualmente, se admita a existência de riscos profissionais, mesmo que o número de especialistas nesta matéria tenha vindo a aumentar e mesmo que os estudos neste domínio se multipliquem, tudo parece contribuir para a ideia de que o estado de saúde da maioria dos trabalhadores é satisfatório e que as reais patologias, como os grandes acidentes de trabalho, são excepções.

9 É a partir desta constatação que descrevemos o trabalho de Carla Barros-Duarte (2004), que teve como objectivo contrariar o conjunto destas dinâmicas que se reforçam mutuamente e se auto-reproduzem, tornando socialmente invisíveis os efeitos do trabalho na evolução da saúde de muitos trabalhadores.

Deste modo, a abordagem é articulada por diferentes etapas, no seio das quais são privilegiadas, sobre o plano metodológico, determinadas opções.

11 O ponto de partida consistiu numa leitura de dados estatísticos, complementada por um inquérito centrado no estudo da evolução da saúde induzida pelas condições de trabalho. Esta abordagem global evidenciou a necessidade de uma análise "local», apoiada pela tradição científica contemporânea da psicologia do trabalho e da ergonomia : o objectivo desta etapa foi o de melhor compreender a forma como cada um gere os constrangimentos do trabalho a fim de preservar o seu equilíbrio. No entanto, se, nesta etapa, o objectivo era o de realçar uma démarche susceptível de transformar certas dinâmicas desenvolvidas nas empresas, ela evidenciou, também, o interesse de conceber um modelo de intervenção que se situasse mais claramente num plano de aç̧ão pública, nomeadamente a nível regional. Desta forma, a abordagem desenvolveu-se em termos de saúde pública, à semelhança da experiência desenvolvida 
há já alguns anos na região de Bouches du Rhône, em França, com o apoio de Ivar Oddone. De facto, o debate relativo à acção pública alargou a perspectiva do estudo e contribuiu para o alargamento do sentido de certas questões de investigação : permitiu, nomeadamente, definir melhor as intervenções susceptíveis de contribuir para uma outra transparência dos dados e dos processos analisados.

Estas conclusões vão de encontro a uma recente alteração no tratamento dos dados estatísticos relativos às doenças profissionais, assim como a certas iniciativas de aproximação de diferentes actores, num projecto baseado em novas modalidades de gestão do risco profissional.

\section{Saúde e trabalho: os silêncios dos números oficiais}

Em Portugal, a preocupação em melhorar o sistema de informação no domínio da saúde tem conduzido à criação de departamentos e organismos específicos que, com alguma periodicidade, realizam estudos sobre a evolução do estado de saúde dos portugueses (Ministério da Saúde, 2002 ; Observatório Português dos Sistemas de Saúde, 2005). Estes balanços demonstram melhorias globais, nomeadamente graças à redução das doenças transmissíveis e à diminuição das taxas de mortalidade infantil.

Todavia, estas análises - mesmo se se ponderar a fidelidade dos dados publicados, evidenciando claras tendências de uma sub-declaração dos casos de doenças transmissíveis (Direcção Geral da Saúde, 2005) - revelam, por outro lado, que as preocupações da saúde pública se mostram pouco atentas ao impacto do contexto profissional no bem-estar dos cidadãos. Procura-se, então, delimitar os problemas de saúde, tais como se manifestam no indivíduo considerado isoladamente, num diálogo singular, próprio ao gabinete médico.

15 À semelhança do que se constata noutros contextos, o domínio dos problemas de saúde relacionados com a actividade profissional acabam por ser ocultados no seio desses estudos - como se o processo de reconhecimento das doenças profissionais fosse suficiente para garantir o reconhecimento colectivo dos problemas mais flagrantes da saúde no trabalho.

$\mathrm{Na}$ verdade, é sabido o quanto "a declaração e o reconhecimento das doenças profissionais resultam de processos longos, complexos, selectivos e pouco sistemáticos, que excluem ao longo do procedimento numerosos casos" (Thébaud-Mony, 1991, tradução livre). Na realidade, para o reconhecimento de uma nova doença profissional, o processo de decisão mistura "inextrincavelmente o conhecimento científico do perigo e arbitragem sócio-económica” (Henry, 2004, p. 299, tradução livre) e é atravessado, frequentemente, por difíceis negociações entre parceiros sociais.

Deste modo, numerosos problemas de saúde relacionados com o trabalho exercido, não transparecem nos dados oficiais que, supostamente, classificam as pessoas que sofreram os efeitos dos riscos dos locais onde exerceram a sua actividade profissional quer seja por falhas no longo processo de identificação da origem profissional da patologia até à sua declaração e posterior reconhecimento, quer seja pela organização e sistematização dos dados, que deixa muito a desejar no plano da sua transparência (ver tabela 1).

Sinopse 1 
Em Portugal, até 2000 [1], a evolução das doenças profissionais - oficialmente reconhecidas pelo Centro Nacional de Protecção contra os Riscos Profissionais [ ${ }^{2}$ ] (CNPRP) - aponta para um ligeiro aumento gradual do número de pensionistas com incapacidade permanente [3].

No conjunto, os casos mais frequentes de doenças profissionais [ $\left.{ }^{4}\right]$ são as pneumatoses causadas pela inalação de poeiras minerais (na sua maioria silicoses e pneumoconioses) e as doenças provocadas pelo ruído ou por outros “ agentes físicos » (cf. tabela 1).

Estamos, pois, perante uma situação de pouca transparência das estatísticas oficiais, quer sejam consideradas as que são publicadas pelos serviços do Ministério da Saúde, as que são transmitidas pelos serviços do Ministério do Trabalho e da Solidariedade Social.

Esta foi uma das preocupações que suscitou o estudo desenvolvido a partir do Inquérito Saúde, Idade e Trabalho (SIT), que será objecto de análise no ponto seguinte deste artigo.

Tabela 1 : Evolução do número total de pensionistas com incapacidade permanente por tipo de doença profissional (1999-2000)

\begin{tabular}{|c|c|c|c|c|c|c|c|c|c|c|c|}
\hline & 1990 & 1991 & 1992 & 1993 & 1994 & 1995 & 1996 & 1997 & 1998 & 1999 & 2000 \\
\hline Intoxicaçōes & 184 & 199 & 207 & 219 & 226 & 242 & 253 & 260 & 266 & 274 & 282 \\
\hline Pneumatoses & 10460 & 10460 & 10346 & 10354 & 10350 & 10316 & 10492 & 10459 & 10216 & 10040 & 9955 \\
\hline Dermatoses & 975 & 1079 & 1239 & 1374 & 1485 & 1640 & 1768 & 1844 & 1926 & 2078 & 2203 \\
\hline Agentes fisicos & 3611 & 3797 & 3914 & 4255 & 4716 & 5309 & 5545 & 5757 & 5941 & 6314 & 6549 \\
\hline $\begin{array}{c}\text { Sequelas de } \\
\text { acidentes de } \\
\text { trabalho [5] }\end{array}$ & - & - & - & - & 667 & 739 & 739 & 739 & 739 & 739 & 739 \\
\hline \begin{tabular}{c} 
Outras [6] \\
\hline Total
\end{tabular} & 15936 & 16339 & 16558 & 17123 & 17816 & 18649 & 19202 & 19475 & 19501 & 19864 & 20150 \\
\hline
\end{tabular}

Sequelas de acidentes de trabalho [5] Outras [6]

\section{2. À procura do ângulo morto (Thébaud-Mony, 1991)}

Como já foi realçado, as consequências do trabalho na saúde não têm, normalmente, uma expressão imediata e linear e, embora acompanhem todo o ciclo de vida do indivíduo, manifestam-se frequentemente de forma diferida e singular (Gollac \& Volkoff, 2000). Na realidade, as condições de trabalho são vividas, por cada um, de forma diferente e os seus efeitos dependem não só do percurso profissional e do contexto de trabalho, mas também da percepção que cada um pode ter em função das suas especificidades físicas, psicológicas e sociais. 
Esta diversidade e variabilidade envolvem a compreensão de um conjunto de factores que interagem mutuamente e a diferentes níveis nos vários momentos da vida - o que exige uma abordagem atenta e diferenciada, que não negligencie a necessidade de integrar na história de cada indivíduo as condições de trabalho actuais, mas também as vividas anteriormente (Volkoff, Molinié \& Jolivet, 2000). Por esta razão, considera-se que é imprescindível ter em consideração a idade no estudo da relação com o trabalho, de modo a evidenciar o que, no ambiente construído pelo homem, acabou por influenciar significativamente a história individual.

o paradigma privilegiado distingue-se, portanto, dos estudos subjacentes aos dados oficiais, já que para além das doenças profissionais flagrantes, regista-se, também, um conjunto de outras evoluções induzidas pelas condições de trabalho que deixam - ou deixaram - a desejar.

21 Neste espírito, e na linha de uma tradição já bem implementada em França, um instrumento de investigação foi concebido de modo a ser suficientemente amplo para analisar as diversas dimensões das relações entre saúde e trabalho, e suficientemente discriminativo para registar todas as particularidades dessas relações.

É de salientar o carácter experimental desta fase da investigação realizada em Portugal, já que corresponde à concepção e à primeira aplicação do Inquérito SIT, promovida pelo Instituto de Desenvolvimento e Inspecção das Condições de Trabalho (IDICT), no âmbito da Campanha para a Melhoria das Condições de Trabalho na Indústria Têxtil e do Vestuário [6]. Assim, neste caso particular, adoptou-se uma metodologia centrada na análise transversal, diferente da perspectiva longitudinal específica aos inquéritos ESTEV e VISAT realizados em França.

Sinopse 2

O Inquérito SIT, inspirado nos inquéritos franceses ESTEV e VISAT.

O Inquérito ESTEV (Inquérito Saúde, Trabalho e Envelhecimento) foi concebido no final dos anos 80 no seguimento de um projecto de médicos do trabalho que, com a colaboração de equipas de investigação em epidemiologia, gerontologia e ergonomia, decidiram desenvolver um inquérito de grande amplitude sobre a evolução da saúde com a idade, no contexto de trabalho. $O$ inquérito foi realizado no âmbito das visitas anuais da medicina do trabalho em 1990 e 1995. A amostra no início do estudo era constituída por 21378 trabalhadores e, posteriormente, $87 \%$ da amostra foi de novo analisada. A metodologia teve nomeadamente o objectivo de, a partir da recolha de uma quantidade diversa de informações, quer no domínio da saúde quer no domínio do trabalho, preparar os procedimentos necessários para iniciar os estudos longitudinais (Coutrot \& Wolff, 2005). 0 inquérito é composto por 5 questionários, fornecendo assim, para cada trabalhador, numerosas informações sobre a sua vida de trabalho actual e passada e sobre o seu estado de saúde, este último também avaliado através de um questionário de auto-avaliação da saúde e um exame médico detalhado (Derriennic, Touranchet, \& Volkoff, 1996).

O Inquérito VISAT (Envelhecimento, Saúde e Trabalho) insere-se num estudo organizado por uma centena de médicos do traba ho de três regiões do sul de França e por uma equipa de investigadores especializados no estudo do 
envelhecimento, da ergonomia e da saúde no trabalho. As questões formuladas inscrevem-se na lógica do Inquérito ESTEV, procurando avaliar de forma mais precisa as evoluções dos trabalhadores no plano cognitivo. Duas aplicações foram realizadas : a primeira em 1996 (3237 trabalhadores) e a segunda em 2001 (Marquié et al., 2002).

Para a concepção do inquérito SIT, além do que exige a adaptação deste tipo de instrumento a uma outra realidade linguística e social, foi necessário ter em consideração a especificidade dos interlocutores que participaram nesta fase exploratória - os trabalhadores dos sectores da indústria têxtil e do vestuário. Neste sentido, certos itens foram incluídos, a formulação de algumas questões foi revista e foi reorganizada a sequência de alguns capítulos.

Mas a estrutura do inquérito mantém-se semelhante aos inquéritos ESTEV e VISAT e reagrupa os itens que dizem respeito :

- às características gerais e profissionais do trabalhador : é constituída por questões gerais sobre o trabalhador e a profissão ; um conjunto de características relativas às condições de trabalho actuais e passadas (nomeadamente, a duração da exposição), com o objectivo de integrar todo o percurso profissional do trabalhador ; uma análise mais exaustiva do trabalho actual ; uma avaliação das principais dificuldades sentidas pelo trabalhador na realização das suas actividades ; índices relativos à qualidade do repouso e do sono; um conjunto de questões de (auto)apreciação do estado de saúde (que correspondem à aplicação da versão portuguesa do Perfil de Saúde de Nottingham [7]) ; um conjunto de questões relativas às características do indivíduo e da sua vida fora do tempo de trabalho de modo a permitir uma compreensão mais ampla do que pode ser susceptível de ter influenciado o seu percurso ;

- as informações médicas - além da avaliação de alguns indicadores específicos ao exame médico tradicional, procede-se a um inventário de patologias actuais e passadas, dos acidentes e doenças profissionais, assim como à descrição dos medicamentos consumidos ; está também previsto, um suplemento dirigido especificamente às mulheres, relativo a informações sobre a gravidez, a contracepção e a menopausa ;

- assim como o inquérito VISAT, alguns dados relativos às capacidades cognitivas (memória, atenção,...) foram avaliados através de um conjunto de provas psicotécnicas clássicas.

Para esta primeira aplicação do inquérito SIT, teve-se particularmente em atenção as condições de realização das entrevistas que iriam sustentar a produção de dados. Nos primeiros ensaios demonstrou-se a necessidade de recorrer a uma situação de entrevista individual, conjugando a colaboração de psicólogos do trabalho, membros da equipa de investigação e a dos médicos das empresas participantes no estudo.

Por outro lado, a boa compreensão dos dados recolhidos relativamente às condições de trabalho descritas pelos trabalhadores exigia que a análise fosse enriquecida por metodologias complementares: deste modo, optou-se por recorrer a uma caracterização das empresas onde os 329 trabalhadores interrogados exerciam a sua 
função - evidenciando em particular a evolução da organização do trabalho e dos processos produtivos - e a realização de uma análise ergonómica de algumas actividades principais deste sector.

\section{Contributos e limites da análise transversal}

Sem apresentar aqui, de forma detalhada, a aplicação do inquérito SIT (Barros-Duarte, Ramos, Cunha, \& Lacomblez, 2002), assinala-se que, globalmente, os diversos indicadores analisados revelam uma deterioração precoce do estado de saúde de um número significativo de trabalhadores - quer devido às características do exercício da sua actividade profissional actual, quer devido às condições de trabalho a que estiveram expostos no passado - mas que, contudo, são avaliadas de forma diferente, na sua natureza e na sua importância, pelos trabalhadores, por um lado, e pelos médicos do trabalho, por outro.

A tabela 2 evidencia, aliás, os principais constrangimentos do trabalho actual e passado dos trabalhadores analisados na amostra estudada. Como se pode constatar, é essencial distinguir os dados segundo a sua distribuição por género, já que existem áreas predominantemente ocupadas por homens - $57 \%$ dos homens trabalha na fiação, na tecelagem, na tinturaria e acabamentos e manutenção e $43 \%$ das mulheres asseguram preferencialmente áreas como a tecelagem, a confecção e o embalamento - estas funções estão associadas a uma organização e a condições de trabalho bem específicas.

Tabela 2 : Principais constrangimentos do trabalho actual e passado, segundo o género dos trabalhadores (em percentagem)

\begin{tabular}{|l|c|c|c|c|c|c|}
\hline \multirow{2}{*}{ Constrangimentos } & \multicolumn{3}{|c|}{ Sim, actualmente } & $\begin{array}{r}\text { Não actualmente, mas } \\
\text { sim no passado }\end{array}$ & \multicolumn{2}{c|}{ Total } \\
\cline { 2 - 8 } & Homens & Mulheres & Homens & Mulheres & Homens & Mulheres \\
\hline Barulho intenso & 57.8 & 26.1 & 12.8 & 12.7 & 70.6 & 38.8 \\
\hline $\begin{array}{l}\text { Exposição a poeiras e } \\
\text { gases }\end{array}$ & 66.3 & 55.6 & 16.6 & 14.8 & 82.9 & 70.4 \\
\hline $\begin{array}{l}\text { Trabalho que obriga a } \\
\text { adoptar posturas peno- } \\
\text { sas ou cansativas }\end{array}$ & 70.6 & 78.9 & 12.3 & 4.9 & 82.9 & 83.8 \\
\hline $\begin{array}{l}\text { Trabatho que obriga a } \\
\text { carregar cargas pesa } \\
\text { das ou a esforços fisi- } \\
\text { cos intensos }\end{array}$ & 54.5 & 32.4 & 17.6 & 13.4 & 72.1 & 45.8 \\
\hline $\begin{array}{l}\text { Possibilidade de es- } \\
\text { colher os momentos } \\
\text { de pausas }\end{array}$ & 77.7 & 27.7 & $*$ & $*$ & 77.7 & 27.2 \\
\hline
\end{tabular}

* valores não disponíveis Fonte : Barros Duarte, 2004

27 A análise do conjunto dos dados permite identificar as principais tendências, referidas pelos trabalhadores do sector, relativamente aos riscos profissionais. Torna-se, assim, importante avaliar os efeitos ao nível da evolução do estado de saúde destes trabalhadores, a partir das informações médicas disponíveis (ver Sinopse 2). 
De facto, o cruzamento dos dados revela uma décalage significativa de um número considerável de avaliações.

Os médicos referem $16.4 \%$ de casos de doenças do sistema osteoarticular e muscular e $55.8 \%$ dos trabalhadores referem dificuldades na realização de esforços físicos intensos assim como na adopção de posturas penosas ou cansativas e $41 \%$ queixam-se de limitações no plano da mobilidade física. De facto, a proporção de trabalhadores que fazem explicitamente referência a este tipo de problemas é, portanto, bem maior do que aquilo que transparece na avaliação dos médicos.

As informações relativas à exposição ao ruído evidenciam, igualmente, este desfasamento - mesmo tratando-se de um dos riscos mais importantes no sector em questão, em particular para os homens (ver tabela 2). Neste caso, os médicos referiram $6.7 \%$ de riscos de patologia - embora $34 \%$ dos trabalhadores (e $41.1 \%$ dos homens) indicassem estas dificuldades.

1 No entanto, outros dados mostram que os trabalhadores raramente estabeleciam relações de causalidade entre as características do trabalho e a evolução do seu estado de saúde: não podemos, portanto, concluir que as queixas transmitidas sejam exageradamente persistentes. Por outro lado, $84.8 \%$ dos trabalhadores têm uma percepção positiva da sua saúde. Mas, mesmo neste plano, a opinião dos médicos é discordante, já que consideram que $96.7 \%$ dos trabalhadores examinados gozam de uma saúde muito satisfatória e satisfatória - apesar de terem assinalado que $14.9 \%$ dos trabalhadores consome regularmente psicotrópicos.

32 Ainda que a distância entre o que é referido pelos trabalhadores e o que transparece na avaliação dos médicos seja grande, podemos avançar com algumas hipóteses que contribuem para uma explicação destas aparentes contradições no caso em análise : a relação estabelecida com os psicólogos do trabalho (investigadores externos à empresa) ao longo das entrevistas foi de natureza diferente daquela que caracteriza o exame médico - a vontade de escutar caracteriza a primeira relação e a preocupação no rigor a segunda, que tem subjacente uma lógica inerente ao diagnóstico médico, sempre impregnada "da questão médica relativa à presunção de origem" (Thébaud-Mony, 1991, p. 109, tradução livre). Contudo, é necessário relembrar que o discurso do trabalhador, no seu encontro com o médico do trabalho, é frequentemente atravessado pela incerteza da relação entre o veredicto final e os efeitos deste sobre o decurso da sua vida : assim, como o referia Canguilhem, (2002, p. 62 e 63, tradução livre) “ a saúde não é somente a vida no silêncio dos órgãos, é também a vida na discrição das relações sociais. Se eu digo que estou bem, impeço que se profiram quaisquer interrogações. Se eu digo que estou mal, as pessoas querem saber como e porquê, e o interesse por um problema orgânico individual transforma-se, eventualmente, num interesse para os défices orçamentais de uma instituição".

33 Na realidade, trata-se da dificuldade em exprimir o conjunto de problemas de saúde infra-patológicos, sem gravidade evidente, não merecendo explicitação, frequentemente associados à evolução "natural" da idade, e que abarca, geralmente, a diminuição da audição, as dores articulares, os problemas de sono, a sensação de fadiga, a ansiedade, o consumo de tranquilizantes (Molinié \& Volkoff, 2002), mas que sem a mudança das condições em que se exerce a actividade de trabalho são susceptíveis de se concretizarem em problemas físicos ou psicológicos profundos. 
Tendo em consideração a nossa preocupação inicial, esta constatação levantou interrogações de ordem metodológica: se a abordagem transversal do inquérito SIT apresentou, de facto, uma contribuição fundamental nomeadamente para a caracterização das condições de trabalho do sector, paradoxalmente, com este contributo poder-se-ia correr o risco de produzir invisibilidade (Daubas-Letourneux, 2004), se uma análise mais aprofundada das interpretações de certas contradições aparentes nos resultados obtidos não fosse desenvolvida, situando-as, mais concretamente, face às outras opções metodológicas da investigação - nomeadamente, as entrevistas e as análises de actividade. 0 reconhecimento dos efeitos do trabalho sobre as evoluções da saúde dos trabalhadores passa, nomeadamente, por um processo de tomada de consciência do próprio trabalhador e pelo diálogo que pode ser estabelecido com os profissionais de saúde - compreendemos o significado que este encontro poderia ter no desenvolvimento de uma outra dinâmica.

Esta reflexão insere-se, agora, a um nível "local », orientado para uma análise das acções e das interacções face a face entre os diferentes actores envolvidos, estimulando a evolução da compreensão do fenómeno global que pretendemos estudar.

\section{Gestão dos riscos e discrição: os contributos da análise ergonómica do trabalho e o papel decisivo do colectivo}

36 Este estudo desenvolvido a um nível “ local » foi realizado com a colaboração de 12 trabalhadores que participaram no Inquérito SIT e que exerciam a sua actividade profissional na secção de tecelagem de uma empresa-participante.

O objectivo desta fase da investigação era compreender as estratégias desenvolvidas pelos trabalhadores na gestão e preservação da sua saúde. Pretendia-se alargar o debate relativo aos efeitos das condições de realização da actividade profissional e definir com os próprios trabalhadores propostas para uma transformação do trabalho. Nesta perspectiva, foram privilegiados os princípios teórico-metodológicos específicos a uma tradição científica da ergonomia e de certas correntes da psicologia do trabalho, que focalizam a sua análise e o seu projecto de intervenção no estudo dos processos de regulação desenvolvidos pelos trabalhadores graças à experiência adquirida na sua actividade profissional (ver Sinopse 3).

Sinopse 3

Uma tradição da ergonomia (Teiger \& Laville, 1991) contribuiu para fazer emergir práticas de intervenção baseadas numa dinâmica que associa e articula mutuamente a investigação, a formação e a acção. Estas abordagens assentam no reconhecimento dos saberes da experiência específicos dos trabalhadores, valorizam o seu ponto de vista e a ideia de uma aprendizagem recíproca entre investigadores e trabalhadores. Visa-se uma co-produção de conhecimentos entre "os peritos" de domínios diferentes com o objectivo comum de : "compreender o trabalho para o transformar", segundo a proposição de Guérin, Laville, Daniellou, Duraffourg, \& Kerguelen (1992) ; e, como o propõe Oddone, Re, \& Briante (1977), trata-se de agir para a construção "de uma comunidade científica alargada". 
Deste modo, é concebido um paradigma de formação em análise do trabalho. Afastado das formas tradicionais de aprendizagem do tipo escolar, estas acções ergonómicas de formação - que podem ser aplicadas a diferentes públicos para os quais é importante tomar consciência das relações trabalho/saúde - são orientadas para a investigação das possibilidades de agir, a partir da construção colectiva de pistas de transformação. Procuram-se respeitar os seguintes princípios :

- A necessidade de partir das representações e conhecimentos iniciais dos participantes através de descrições pormenorizadas da sua actividade, no seu contexto de trabalho, e dos efeitos sentidos ; estas descrições, primeiro espontâneas, são seguidamente "sustentadas" por um "questionamento ergonómico" - que é de tipo maiêutico porque visa estimular a actividade reflexiva e permitir "pôr em palavras" o que nem sempre se sabe que se sabe.

Conhecimentos novos sobre a situação e sobre si mesmo são, assim, construídos pelo exercício de reflexão e de expressão, e esta construção pode mesmo prosseguir bem para além do período específico da formação ;

- A preocupação em "trabalhar a linguagem" a fim de facilitar a troca e a confrontação dos conhecimentos da experiência dos participantes entre si, por um lado, e estes com os conhecimentos "disciplinares" dos ergónomos, por outro lado. Por vezes, relações inéditas e impensáveis adquirem outra visibilidade e tornam-se também "dizíveis" e partilháveis. Pode-se então passar, progressivamente, da formulação de problemas à sua formalização e à sua desindividualização, o que amplia as possibilidades de acção colectiva ;

- A preocupação em introduzir os conhecimentos "ergonómicos" de forma "oportuna", em função das questões que se colocam e não de acordo com um programa pré-estabelecido, permite que surjam de forma relevante e, por isso, sejam mais bem compreendidos e melhor apreendidos. Três tipos de conhecimentos são, então, referidos : "ergonómicos" (modelos da actividade, relações estabelecidas entre a saúde/trabalho), "metodológicos" (a démarche e os métodos da análise ergonómica do trabalho), "estratégicos" (critérios de análise das condições de viabilidade : constrangimentos e recursos) para uma acção "situada" sobre o trabalho, o seu acompanhamento e a sua continuidade na empresa.

A aprendizagem da análise ergonómica do trabalho é concebida aqui como "um instrumento para a acção" na perspectiva construtivista piagetiana, segundo a qual qualquer conhecimento consiste não em copiar o real, mas em agir sobre ele e transformá-lo, em aparência ou em realidade, de maneira a compreendê-lo (Piaget, 1974). A aç̧ão concebe-se, então, em sentido lato, o essencial é transformar as representações, frequentemente redutoras do trabalho e da prevenção "em representações para a acção", fornecendo bases "objectivadas" de análise das situações e de argumentação para mudanças a operar (Teiger, 1993).

A panóplia de aplicações deste modelo "de formação situada" abrange projectos com configurações diversas; mas em todas as fórmulas, estas situações de formação apoiam um processo que valida e generaliza os conhecimentos sobre o 
trabalho que permaneceram até então de tipo clínico, e suscita novas hipóteses ; são efectivamente um lugar de aprendizagem recíproca.

Fontes : Lacomblez (2001); Teiger (2002); Teiger \& Lacomblez (2005; 2006)

O diálogo, previamente definido no âmbito do inquérito SIT, foi assim restabelecido com estes 12 trabalhadores e o objectivo era o de colocar, desta vez, a tónica sobre a maneira como cada um coabitava com o risco de acidente ou de doença profissional.

Esta intervenção desenvolveu-se durante vários meses e recorreu a um conjunto de instrumentos metodológicos, hoje tradicionais para a tradição científica adoptada, que articulam a análise da actividade de trabalho com a condução de entrevistas individuais seguidas de entrevistas colectivas, de auto-confrontações simples e/ou cruzadas (Clot, Fäita, Fernandez \& Scheller, 2000), não negligenciando, contudo, outras reuniões colectivas, por vezes, na presença do médico do trabalho. Este conjunto de estratégias metodológicas implicou, ainda, uma sucessão de momentos de restituição do conteúdo das entrevistas, das análises desenvolvidas e sua articulação com os resultados do inquérito SIT.

Relativamente aos resultados desta fase da investigação, acentua-se aqui a necessidade de evidenciar que, apesar de no diálogo estabelecido com os trabalhadores, as categorias identificadas distinguirem diferentes factores de risco para os peritos em saúde no trabalho, não são necessariamente vividas de maneira diferente e segmentada pelos trabalhadores - ou serem objecto de um outro tipo de categorização. Esta assimetria das categorias de análise, já analisada por Oddone (1999) e recordada por Molinié (2003), atravessou todo o percurso desta intervenção, apoiando-se num processo de interpretação recíproca, que, indubitavelmente, contribuiu para a construção do que Oddone et al. (1977) chamaram de uma comunidade científica alargada.

Mas os contributos desta experiência referem-se, igualmente, à evolução das perspectivas dos trabalhadores relativamente à forma como, progressivamente, descreveram, justificaram e explicitaram a sua gestão de riscos no local de trabalho.

Inicialmente, as análises da actividade em situação de trabalho e as entrevistas individuais facilitaram a criação de um novo espaço, dando lugar à emergência de uma grande variedade de modos de regulação, assumidos por cada um, de forma a conciliar o cumprimento das normas de produção e a preservação de um mínimo de bem-estar. Relembrando os trabalhos De La Garza e Weill-Fassina (2000) a actividade de trabalho é uma forma de estabelecer um equilíbrio entre o sistema de produção, o próprio trabalhador e os outros - podemos concluir que o diálogo com o investigador facilitou a explicitação da dinâmica entre si próprio e o sistema de produção ; ou seja, favoreceu uma referência explícita das suas características antropométricas e morfológicas ou das suas dores osteoarticulares para, assim, justificar as regulações operacionais (Faverge, 1966) que permitiram encontrar outras soluções na maneira de realizar as tarefas ("É, é mais rápido. É mais rápido para mim, que sou pequena, de me esticar ao máximo para meter a malha rapidamente »). Ou, noutras situações, invocam-se, com menor discrição, as regulações que emergem da catacrese (De Keyser, 1972) visto que, nestes casos, altera-se a finalidade inicial de um instrumento ou uma acção para diminuir o mal-estar ou o sofrimento ("Sim, todo o tempo de pé. Eu às vezes ao meter o fio até me sento em cima do tecido, porque sou baixa e às vezes sento-me de lado, em cima do tear 
e meto o fio, porque é sempre de pé »; “ Sim, sim, às vezes também se canta, que é para se esquecer que aquilo está a andar mal, isto é uma forma de se esquecer as coisas portanto a gente canta e reza... »).

No entanto, para além destas constatações, já conhecidas pela ergonomia e pela psicologia do trabalho, é necessário, provavelmente, realçar os momentos de discussão colectiva nos quais foram debatidos os riscos específicos da empresa, os seus efeitos potenciais sobre a saúde e as estratégias de regulação desenvolvidas por cada um, já que se revelaram decisivos na evolução da argumentação dos trabalhadores na qual emergiram, progressivamente, valores que tinham subjacentes um direito à saúde.

\footnotetext{
“Nós não queremos meter aqui os filhos no meio dos teares porque queremos um futuro diferente para os nossos filhos, temos de ser mais bem pagos ".

"Para as máquinas é melhor mas para o trabalhador é pior, este ar condicionado é pior, trabalha-se com muita humidade »

“Antigamente não havia tecelagem sem janelas, nós hoje estamos isolados, mas antigamente não, abria-se uma janela e entrava ar puro, agora não, agora é tudo isolado, nós estamos oito horas num isolamento e num ar impuro, por causa do ar condicionado não se pode abrir portas nem janelas... pronto, mas isto é tudo moderno, agora....e nós temos que nos sujeitar, nós somos feitos da mesma maneira que os trabalhadores de antigamente, não somos diferentes "
}

Sem negligenciar a importância que teve o diálogo com o médico do trabalho bem como a apresentação ao grupo dos resultados do inquérito SIT, podemos avançar a hipótese que a situação colectiva, em si, desempenhou um papel primordial, criando a possibilidade de dizer o que até ali era vivido no silêncio: permitiu esclarecer, desenvolver, definir melhor, recorrer aos contributos da vida fora do trabalho e comparar as maneiras de fazer, as hierarquias de decisões, os esquecimentos, as interpretações, as soluções.

Assim, se nas primeiras etapas da intervenção, a gestão da saúde no trabalho era sobretudo atravessada por preocupações relativamente à gestão do uso de si. Gradualmente, emergiram valores que Yves Schwartz integrou no registo " dos valores sem dimensão » - que se distinguem dos valores de mercado - associados aos valores da política, da deliberação democrática, do direito social, do direito do trabalho (Schwartz, 2000). A situação colectiva de encontro com os pares e os investigadores parece ter desempenhado o papel de uma rede de apoio, integradora e reflexiva.

Contudo, a intervenção deparou-se com um impasse : apesar do interesse inicialmente demonstrado, as entrevistas efectuadas com os diversos responsáveis da empresa mostraram, finalmente, que a abordagem desenvolvida - suportada por um outro reconhecimento dos riscos do trabalho que poderia constituir-se num conjunto de argumentos com vista a um alargamento da sua aplicação às outras equipas de trabalhadores - não encontraria os apoios indispensáveis para o seu prosseguimento.

O trabalho realizado no plano " local » permitiu uma progressão na proposta de um cenário de referência para acções de sensibilização e de informação aos trabalhadores na matéria do (re)conhecimento dos riscos profissionais e dos seus efeitos potenciais. No entanto, na presente fase da investigação, era evidente a necessidade de ir além da acção ao nível da empresa, ultrapassando os constrangimentos metodológicos e de intervenção que lhe são inerentes e situar a investigação no plano da acção pública 
regional: avaliando a este nível os potenciais actores de um processo que se pode apoiar no trabalho já desenvolvido, contornar os obstáculos próprios à dinâmica da empresa e prosseguir, alargando os objectivos iniciais.

\section{Regresso à saúde pública}

A experiência conduzida a partir da década de 80 no território de "Bouches-du-Rhône" em França, por Marco Andeol e Gilbert Igonet, impulsionada por Ivar Oddone (ver Sinopse 4), orientou esta fase da investigação : situando-se ao nível do território - onde se insere a empresa e os trabalhadores participantes na etapa anterior da investigação foi atribuída uma importância particular à prática dos médicos do Centro de Saúde local, que na sua prática de clínica geral e familiar intervêm, também, nos procedimentos de reconhecimento de doença profissional.

\section{Sinopse 4}

Na região de "Bouches-du-Rhône" (Port de Bouc et Martigues), a criação da Association Prise en Charge des Maladies Eliminables teve como objectivo constituir uma rede de apoio, no plano regional, que assumisse um outro reconhecimento das doenças profissionais e, a longo prazo, um saneamento dos locais de trabalho : o objectivo é o de construir arquivos capazes de orientar e estimular quer as acções orientadas para os cuidados de saúde, quer as acções de prevenção.

Parte-se do princípio que todos os dados necessários existem mas que não são acessíveis, nem pelos médicos que devem cuidar da saúde, nem pelos empregadores que devem avaliar o risco, nem pelos trabalhadores que são confrontados com os riscos diariamente, nem mesmo pelos organismos que têm a responsabilidade na gestão da saúde no trabalho. Desde há vários anos, e com o apoio dos poderes públicos, tem sido construída "uma galeria de casos" de doenças profissionais suspeitas ou diagnosticadas na bacia de emprego em questão : foi elaborada de modo a que todos os médicos de Medicina Geral pudessem desenvolver uma outra forma de aprendizagem sobre os doentes afectados, e, desta forma, identificar novos casos ; mas todos os grupos envolvidos empregadores, especialistas do domínio, associações, organismos públicos,... podem sempre utilizar e completar os dados recolhidos. Estes últimos grupos de protagonistas são os mais privilegiados no que, Ivar Oddone, denominou de Sistema de Informação Concreto (SIC), "catalisando" novas relações entre profissionais e os diferentes grupos de actores.

Actualmente, 28 médicos de Medicina Geral e 15 especialistas participam no projecto. Em 2003 foram identificadas 66 doenças elimináveis, 93 em 2004 e resultados equivalentes foram registados para 2005.

Para facultar a consulta dos arquivos, um programa informático permite aceder a uma lista dos dados recolhidos, facilitando, igualmente, a transmissão de informações complementares; o que, associado a um motor de pesquisa permite o acesso a outras fontes de informação. 
Numa primeira fase deste projecto, a descrição do posto de trabalho era central na organização destes dados. Seguidamente, uma estrutura baseada nos casos tornouse mais eficaz. A experiência, com efeito, confirmou que o médico não identifica as situações de trabalho em questão, mas integra-as "numa lista de postos de trabalho" : ele memoriza-as em função dos casos já identificados e resolvidos.

Além disso, parte-se do princípio de que a imputabilidade do risco a que a pessoa está sujeita solicita uma abordagem global que é sustentada pela demonstração da interacção entre "micro ambiente" concretamente definido e a realidade da actividade de trabalho exercida nesse contexto por uma pessoa. Desta forma, não se pode reduzir a uma abordagem meramente analítica, à procura de factores de risco artificialmente isolados uns dos outros. A questão é então : onde estão as informações que permitem ter um conhecimento que apresente os caracteres de uma abordagem global ? E a resposta é : na cabeça das pessoas que, dia após dia, "utilizam" o posto de trabalho, conhecem-no através da sua experiência directa mas também através dos colegas que vivem situações semelhantes. $O$ procedimento é, então, centrado na compreensão da perspectiva do paciente : 0 que permite ao médico descobrir que os seus pacientes são portadores de informações e que, por isso, devem adoptar uma nova leitura do sistema de cuidados de saúde e da própria relação que estabelecem com os médicos. Mas isto fornece, igualmente, material de partida ("um material bruto", "à espera de processamento"), que deve ser construído numa linguagem "conjunta" que facilite a comunicação das informações relativas ao "micro ambiente" e à interface com os outros profissionais.

Os elementos essenciais deste procedimento são estruturados da seguinte maneira :

- Para cada actividade de trabalho é elaborado o seu "currículo laboris", pedindose ao trabalhador que se posicione mentalmente no seu perímetro de trabalho, desenhando-o grosseiramente sobre uma folha ;

- É-lhe fornecido um formulário de identificação dos riscos ("os perigos") concebido de forma a tornar mais permeável a interface entre a pessoa exposta ao risco e o médico, e que permite uma abordagem global organizada em 4 grupos de factores : (1) o que vem ao espírito quando se pensa no posto de trabalho como se se tratasse de um apartamento (barulho, temperatura, iluminação) ; (2) o que vem ao espírito quando se pensa estritamente no meio ambiente de trabalho (poeiras, fumos, gases, vapores, formas de energia, vibrações) ; (3) as situações que produzem fadiga devido a um esforço muscular ; (4) todas as situações que produzem uma fadiga não relacionada com a actividade muscular (posturas, ansiedade, ritmos, horários);

- Obtém-se uma descrição sucinta mas suficiente do posto de trabalho : estas informações estarão acessíveis e serão objecto de trocas de informação com os diferentes grupos de responsáveis, detentores de competências técnicas ou funções sociais diversas. Três elementos caracterizam esta descrição : a superfície real sobre a qual o sujeito se pode deslocar enquanto trabalha; o que faz concreta e realmente a pessoa ("o trabalho real"); as especificidades locais (pretende-se 
recuperar com esta noção o que, numa mesma condição de produção, pode reduzir o risco).

Deste modo, quatro pólos de análise articulam-se e perspectivam intervenções que irão permitir e melhor compreender as situações nocivas e intervir até ao seu saneamento :

1. 0 pólo de análise e tratamento da informação por parte dos médicos dos dados relativos às doenças elimináveis ;

2. O pólo responsável pela análise e organização das informações relativas ao contexto de trabalho, partilhado por todas as organizações presentes no território (organizações não institucionais incluídas);

O pólo de consulta de peritos dos equipamentos e tecnologias (tecnólogos) e do Homem (médicos do trabalho) ;

3. O pólo cuja função é a do saneamento - no sentido de explorar imediatamente os dados existentes e, depois, solicitar outras informações necessárias.

4. O objectivo desta "galeria de casos" é o de produzir uma medicina "cumulativa", de modo a que o médico possa relacionar a sua memória individual, dos casos que foram os seus, àqueles dos colegas, que exercem a sua actividade numa mesma "bacia de vida".

Contudo, a ambição fundamental é a construção e a consolidação de um sistema de saneamento dos locais de trabalho : o saber cumulativo, ao ser informatizado, é disponibilizado a todos os cidadãos, a fim de apoiar intervenções que procurem conceber um desenvolvimento ambiental sustentável.

Fonte : Association pour la Prise en Charge des Maladies Eliminables (2005) ; Le quotidien du médecin (2006).

De facto, o Centro de Saúde em questão enquadra-se bem no projecto em curso nesta fase da investigação: localizado na região norte de Portugal, situa-se numa bacia de emprego onde dominam largamente as indústrias têxtil e do vestuário (cerca de $80 \%$ da população activa ou já reformada exerce ou exerceu a sua actividade profissional neste sector). Assim, nesta etapa, elaborou-se a seguinte hipótese : os problemas de saúde dos trabalhadores participantes nas etapas anteriores da investigação correspondem aos problemas de saúde mais frequentes na região.

Foram realizadas várias entrevistas, privilegiando o diálogo com os médicos de Medicina Geral e Familiar, relativamente aos diferentes aspectos da sua prática no Centro de Saúde e na região.

51 Da análise dos dados recolhidos, constatamos, de facto, uma distância entre o que são as evidências para a saúde pública e as evidências para a saúde no trabalho : a maior parte dos médicos de Medicina Geral e Familiar entrevistados assumem desconhecer as actividades profissionais específicas do sector da indústria têxtil e do vestuário, bem como as condições nas quais são exercidas - considerando, contudo, ser difícil compatibilizar este tipo de preocupação com o número excessivo de pacientes que devem acompanhar. Tal permite, também, explicar que, quando (os médicos) fazem 
referência aos principais problemas de saúde dos seus pacientes, os problemas de surdez profissional, por exemplo, sejam praticamente ignorados - embora dois terços dos utentes deste Centro de Saúde trabalhem ou tenham trabalhado no sector da indústria têxtil e do vestuário e, por isso, uma grande parte esteja exposta a este risco.

Por outro lado, quando as entrevistas se orientaram para os aspectos mais específicos da evolução da saúde dos trabalhadores no sector em causa, os médicos mantiveram esta subavaliação dos problemas auditivos, bem como uma baixa estimativa das patologias respiratórias - mesmo mencionando os riscos de bissinose. Além disso, os problemas reumatismais e, nomeadamente, as lombalgias, bem como as alterações "do sistema nervoso", foram sublinhados por vários médicos.

Esta representação dos riscos contrasta, então, com as análises dos interlocutores das fases anteriores do estudo. Mas este contraste é ainda mais notório se tivermos em conta os dados dos dossiers de declarações de doenças profissionais deste mesmo Centro de Saúde, durante os últimos anos, pois a distribuição das doenças profissionais reconhecidas revela $54 \%$ de casos de surdez profissional e $28 \%$ de bissinose.

A aparente incoerência entre a importância das doenças profissionais reconhecidas e o conteúdo do discurso destes médicos de Medicina Geral e Familiar, constitui um desafio interessante em termos de intervenção : porque, se é evidente que "a grande maioria dos médicos não tem nenhum conhecimento do trabalho industrial (em sentido lato, do trabalho na sociedade industrial) e nenhum estímulo profissional ou financeiro para ter mais" (Thébaud-Mony, 1991, p. 71, tradução livre), o isolamento profissional no qual acabam por assumir as suas funções é flagrante, assim como a ausência de apoio informativo real. Em consequência, a prevenção praticada afasta-se geralmente do local de trabalho, privilegiando o controlo dos factores de risco associados aos comportamentos individuais e a promoção "de estilos de vida saudáveis" (Ministério da Saúde, 2004), dependentes, aparentemente, da boa vontade do trabalhador.

o projecto de implementação de uma rede de profissionais da saúde e da saúde no trabalho emergiu desta reflexão : como na experiência de "Bouches-du-Rhône", trata-se de conceber um dispositivo atento às interfaces entre os diversos grupos de protagonistas, valorizando simultaneamente o contraste dos seus pontos de vista, dado que nenhuma abordagem esgota nunca a questão do trabalho.

Mas se o modelo de referência de Marco Andeol e Gilbert Igonet e a sua experiência constituem contributos fundamentais, não podemos deixar de considerar as práticas desenvolvidas nesta matéria pelos diversos actores em Portugal.

Por outro lado, este debate permitirá uma confrontação de experiências e um incentivo à circulação de conhecimentos, se se tiver subjacente uma recolha de dados baseada em situações concretas e se, igualmente, se encontrar apoio institucional tangível.

Estas convicções justificaram o conjunto das entrevistas realizadas, no fim do percurso desta investigação, com alguns responsáveis políticos locais - considerando que as instâncias do poder local são susceptíveis de desempenhar um papel decisivo na definição de novas estruturas adequadas, e que estas entrevistas poderiam ser susceptíveis de lançar os primeiros dados para uma gestão alternativa de um saneamento regional. 


\section{Perspectivas}

59 A instauração, ao nível do território, de redes e estruturas de apoio que possam favorecer a construção de capacidades individuais e colectivas de debate e acção (Davezies, 2002) no plano do (re)conhecimento das doenças profissionais, passa por uma reflexão crítica em matéria de saúde pública (Dozon \& Fassin, 2001). o desafio é indubitavelmente o encontro de diferentes "culturas políticas da saúde pública": no âmbito do potencial debate entre os diversos protagonistas contactados no percurso desta investigação, teríamos matéria, "não para um saber (enunciando verdades sobre a boa condução da existência) que será confrontado com culturas (supostamente ignorantes ou irreverentes destas verdades), mas sim, para uma interacção entre códigos culturais (formulando uns e outros verdades em relação a teorias locais)" (Dozon \& Fassin, 2001, p. 10, tradução livre).

Mas o projecto de "Bouches du Rhône", ou aquele, ainda em estado embrionário, no Norte de Portugal, exige também uma análise atenta aos desafios a longo prazo, específicos das iniciativas que se situam no campo da economia social, sendo caracterizadas pela sua ancoragem ao nível regional, assim como pela importância atribuída à noção de território, de serviços de proximidade ou de desenvolvimento comunitário (Bidet, 2000). Porque estes projectos não constituem, apenas pelas suas características internas, "uma panaceia que prefigura uma sociedade futura" (Alaluf, 2005, p. 17): se é incontestável que novas formas de gestão territorial, favorecem o desenvolvimento de processos de coordenação multiactores, integrando-os no seio de compromissos renovados entre o global e o local e correspondem hoje a desafios políticos cruciais (Gaudin, 2002), não se pode negligenciar os riscos inerentes à promoção de um "sector terciário" (Evers, 2000), resíduo de uma segunda zona do económico (que visa reparar os estragos da competitividade privada), que seria mantida à margem de um sector público que deixa a desejar.

61 No entanto, alguns indicadores históricos relembram "simultaneamente o peso dos constrangimentos impostos pelos poderes públicos sobre as actividades do sector terciário e a importância das iniciativas criadas no seu seio, à margem das lógicas institucionais públicas, podendo participar de seguida na sua inflexão" (Laville, 2000, p. 548, tradução livre).

Por outro lado, é necessário sublinhar que, após uma recomendação da Comissão Europeia (adoptada em 19 de Setembro de 2003) relativa às doenças profissionais, o Instituto de Informática e Estatística da Segurança Social procedeu a alterações no tratamento e difusão dos dados estatísticos nesta matéria : actualmente (ver Sinopse 5), as informações, disponíveis por cada ano civil, fazem referência aos novos casos de doenças profissionais declarados, bem como aos que foram objecto de reconhecimento ; além disso, a lista das patologias permite distinguir melhor o tipo de doenças, dando outra transparência aos problemas assinalados.

Sinopse 5 
Tabela 3 : Novos casos de doenças professionais reconhecidos (por ano) associados a uma indemnização por incapacidade permanente (2003-2004)

\begin{tabular}{|l|c|c|}
\hline & 2003 & 2004 \\
\hline Asma Profissional & 84 & 105 \\
\hline Conjuntivites & 7 & 6 \\
\hline Conjuntivites e lesōes na córnea & 4 & 0 \\
\hline Dermatites eczematiformes & 26 & 30 \\
\hline Dermatites de contacto & 58 & 81 \\
\hline Dermatites traumáticas & 22 & 16 \\
\hline Fibrose bronco-pulmonar & 6 & 15 \\
\hline Fibrose pulmonar & 125 & 248 \\
\hline Granulomatose & 7 & 0 \\
\hline Granulomatose pulmonar & 22 & 27 \\
\hline Hipoacúsia & 226 & 233 \\
\hline Paralisias & 213 & 453 \\
\hline Tendinites & 321 & 751 \\
\hline Outros & 21 & 58 \\
\hline Total & 1142 & 2023 \\
\hline
\end{tabular}

Fonte : IIESS (2006)

63 Além disso, investigações desenvolvidas em outras regiões de Portugal, relativas à subdeclaração das doenças profissionais, revelam a vontade de certos responsáveis de organismos de saúde pública de incentivar os seus serviços e "assumir um papel mais pró-activo no domínio da saúde dos trabalhadores e na prevenção dos riscos do trabalho" (Castro, Moreira \& Silva Santos, 2005, p. 38).

64 A nossa conclusão é portanto optimista, ainda que especificamente em matéria de condições de trabalho, saibamos bem que os argumentos científicos não são suficientes para uma mudança da relação de força, e que as evoluções das instâncias administrativas se fazem, frequentemente, mais sob o constrangimento de problemas colocados à frente do palco público e político (Henry, 2004).

\section{BIBLIOGRAFIA}

Alaluf, M. (2005). Vieilles et nouvelles définitions. Politique, 39, 15-17. Association pour la Prise en Charge des Maladies Eliminables (2005).

Rapport d'activités 2003-2006 - Evaluation interne de l'utilisation des Fonds d'Aide à la Qualité des Soins en Ville (FAQSV).

Barros-Duarte, C. (2004). Entre o local e o global : processos de regulação para a preservação da saúde no trabalho. Doctoral Thesis, Faculdade de Psicologia e Ciências da Educação, Universidade do Porto, Porto. 
Barros-Duarte, C., Ramos, S., Cunha, L. \& Lacomblez, M. (2002). Da organização do trabalho à saúde ocupacional : análise das condições da actividade profissional na indústria têxtil e do vestuário - a especificidade do trabalho feminino. Porto : IDICT.

Bidet, E. (2000). Economie sociale, nouvelle économie sociale et sociologie économique. Sociologie du travail, 42, 587-599.

Canguilhem, G. (2002). Ecrits sur la médecine. Paris : Éditions du Seuil. Castro, M., Moreira, S. \& Silva Santos, C. (2005). Doenças profissionais na região de Lisboa e Vale do Tejo no ano de 2003 : um contributo para o diagnóstico e prevenção. Segurança, 166, 33-38.

Clot, Y., Faita, D., Fernandez, G. \& Scheller, L. (2000). Entretiens en autoconfrontation croisée : une méthode en clinique de l'activité [version électronique]. Pistes, 2, 1, http:// www.pistes.uqam.ca/v2n1/arti- cles/v2n1a3.htm.

CNPRP (2003). Dados relativos às doenças profissionais nos anos de 2000, 2001 e 2002. Lisboa. Coutrot, Th. \& Wolff, L (2005). L'impact des conditions de travail sur la santé : une expérience méthodologique. Paris : Centre d'Etudes de l'Emploi (http://www.cee-recherche.fr).

Daubas-Letourneux, V. \& Thébaud-Mony, A. (2002). Organisation du travail et santé dans l'Union Européenne. Luxembourg : Office des Publications Officielles des Communautés Européennes.

Daubas-Letourneux, V. (2004). Accidents du travail : des accidents de parcours ? Regards croisés sur la (re)construction de la santé et sur le parcours professionnel de victimes d'accidents du travail. Les évolutions de la santé au cours de la vie professionnelle : altération, préservation, construction, séminaire Vieillissement et Travail, CRÉAPT-EPHE. Paris : Centre d'Etudes de l'Emploi (http://www.ceerecherche.fr).

Davezies, P. (2002). Bilan et défis. Prévention-Sécurité, 61, 30-38.

De Keyser, V. (1972). Fiabilité et expérience. In CECA, Études de Physiologie et de Psychologie du Travail, nำ 7, Fiabilité et Sécurité Eléments pour une ergonomie des systèmes en milieu industriel (pp. 77-137). Luxembourg : Diffusion des Connaissances - Commission des Communautés Européennes.

De La Garza, C., \& Weill-Fassina, A. (2000). Régulations horizontales et verticales du risque. In T. Benchekroun \& A. Weill-Fassina (Eds.), Le travail collectif. Perspectives actuelles en ergonomie (pp. 217-234). Toulouse : Éditions Octarès.

Derriennic, F., Touranchet, A. \& Volkoff, S. (1996). Age, travail, santé. Paris : Les Editions INSERM. Direcção Geral da Saúde (2005). Vigilância epidemiológica - Doenças de declaração obrigatória [version électronique]. Retirado em 3 de Fevereiro de 2006, de http://www.dgsaude.pt .

Dozon, J.P. \& Fassin, D. (2001). Critique de la santé publique. Paris : Balland.

Evers, A. (2000). Les dimensions sociopolitiques du tiers secteur - Les contributions théoriques européennes sur la protection sociale et l'économie plurielles. Sociologie du travail, 42, 567-585.

Faverge, J.M. (1966). L'analyse du travail en terme de régulation. In : J.M. Faverge, M. Olivier, J. Delahaut, P. Stephaneck \& J.C. Falmagne. (Eds.), L'ergonomie des processus industriels (pp. 33-60). Bruxelles : Editions de l'Institut de Sociologie, Université de Bruxelles. Gaudin, J.P. (2002). Pourquoi la gouvernance? Paris : Presses de Sciences Po. Gollac, M. \& Volkoff, S. (2000). Les conditions de travail. Paris : Editions La Découverte. Guérin, F., Laville, A., Daniellou, F. Duraffourg, J. \& Kerguelen, A. (1992). Comprendre le travail pour le transformer. Montrouge : Editions de l'ANACT (rééd. 1997). 
Henry, E. (2004). Quand l'action publique devient nécessaire : qu'a signifié “ résoudre » la crise de l'amiante ? Revue française de science politique, 54, 2, 289-314.

IIES (1999). Séries estatísticas 1990/1998 da Segurança Social. Lisboa : IIES Ministério do Trabalho e da Solidariedade.

IIES (2003). Dados estatísticos relativos às doenças profissionais : pensionistas com incapacidade permanente de 1999/2000. Lisboa : IIES

Unidade de Estatística. IIESS (2006). Dados estatísticos relativos às doenças profissionais [version électronique]. Retirado em 3 de Fevereiro de 2006, de www.seg-social.pt .

INRS (1996). Définition de la santé au travail. Conclusions et recommandations du Comité mixte OIT/OMS de la santé au travail. Documents pour le médecin du travail, 66, 91-93.

Lacomblez, M. (2000). Factores psicossociais associados aos riscos emergentes. Riscos emergentes da nova organização do trabalho. Lisboa : IDICT.

Lacomblez, M. (2001). Analyse du travail et élaboration des programmes de formation professionnelle. Relations Industrielles/Industrial Relations, 56, 3, 543-578.

Laville, J.L. (2000). Le tiers secteur - Un objet d'étude pour la sociologie économique. Sociologie du travail, 42, 531-550.

Le quotidien du médecin (2006). Le quotidien du médecin [version électronique]. Retirado em 7 de Fevereiro de 2006, de http://www.quotimed.com/journal/index.cfm? fuseaction=viewarticle\&DartIdx=22113243k .

Marquié, J-C. (1999). Quelques composantes psychiques et cognitives de la relation âge, travail, santé. Colloque Santé, Travail, Vieillissement : Relations et Évolutions. Paris : CREAPT.

Marquié, J-C., Paumès, D. \& Volkoff, S. (1995). Le travail au fil de l'âge. Toulouse : Éditions Octarès.

Marquié, J.C., Jansou, P., Baracat, B., Martinaud, C., Gonon, O., Niezborala, M., Ruidavets, J.B., Fonds, H. \& Esquirol, Y. (2002). Aging, health, work : overview and methodology of the VISAT prospective study. Le Travail Humain, 65, 3, 243-260.

Ministério da Saúde (2002). Ganhos de saúde em Portugal. Ponto de situação [version électronique]. Retirado a 24 de Março de 2004, de http://www.dgsaude.pt .

Ministério da Saúde (2004). Programa nacional de intervenção integrada sobre determinantes da saúde relacionados com os estilos de vida [version électronique]. Retirado em 10 de Abril de 2005, de http://www.dgsaude.pt .

Molinié, A.F. (2003). Interroger les salariés sur leur passé professionnel : le sens des discordances. Revue Epidémiologique Santé Publique, 51, 589-605.

Molinié, A-F. \& Volkoff, S. (2002). La démographie du travail pour anticiper le vieillissement. Paris : ANACT.

Observatório Português dos Sistemas de Saúde (2005). Relatório de primavera de 2005 : o estado da saúde e a saúde do Estado. Lisboa : Escola Nacional de Saúde Pública.

Oddone, I. (1999). Psicologia dell'organizzazione della salute. Psicología della Salute, Fascicolo 1.

Oddone, I., Re, A. \& Briante, G. (1977). Esperianza operaia, coscienza di classe e psicologia del lavoro. Torino : Einaudi (traduction française : Redécouvrir l'expérience ouvrière. Vers une autre psychologie du travail. Paris : Editions sociales, 1981).

Piaget, J. (1974). La prise de conscience. Paris : PUF. 
Schwartz, Y. (2000). Le paradigme ergologique ou un métier de philosophe. Toulouse : Octarès.

Teiger, C. (1989). Le vieillissement différentiel par et dans le travail : un vieux problème dans un contexte récent. Le Travail Humain, 52, 1, 21-56.

Teiger, C. (1993). Représentation du travail, travail de la Représentation. In A. Weill-Fassina, P. Rabardel \& D. Dubois (Eds.), Représentations pour l'action (pp. 311-344). Toulouse : Octarès.

Teiger, C. (2002). Origines et évolutions de la formation à la prévention des risques “ gestes et postures » en France. Relations Industrielles/ Industrial Relations, 57, 3, 431-462.

Teiger, C \& Lacomblez, M. (2005). L'ergonmie et la trans-formation du travail et/ou des personnes - Permanences et évolutions (1ère partie). Education Permanente, 165, 9-28.

Teiger, C \& Lacomblez, M. (2006). L'ergonmie et la trans-formation du travail et/ou des personnes - Permanences et évolutions (2ème partie). Education Permanente, 166, 9-28.

Teiger, C. \& Laville, A. (1991). L'apprentissage de l'analyse ergonomique du travail, outil d'une formation pour l'action. Travail et emploi, 1, 47, 53-62.

Thébaud-Mony, A. (1991). La reconnaissance des maladies professionnelles : acteurs et logiques sociales. Paris : La Documentation Française.

Volkoff, S., Molinié, A-F., \& Jolivet, A. (2000). Efficaces à tout âge ? Vieillissement démographique et activités de travail. Paris : Dossier du Centre d'Études de l'Emploi, nº 16.

\section{NOTAS}

1. Até ao início de 2005 , os dados oficiais não continham informações relativas aos anos posteriores a 2000. Dados mais recentes serão apresentados na conclusão deste artigo.

2. O CNPRP, organismo do Ministério da Segurança Social e do Trabalho, é responsável pelo reconhecimento e indemnização das doenças profissionais. É a partir dos dados fornecidos por este organismo que o Instituto de Informática e Estatística da Solidariedade (IIES) trata e analisa os dados estatisticamente.

3. Os valores habitualmente utilizados referem-se às doenças profissionais que, tendo sido reconhecidas, resultaram numa incapacidade permanente. Contudo, os valores relativos às doenças profissionais sem incapacidade permanente são também elevados, correspondendo no ano de 2000 a cerca de metade dos novos casos reconhecidos, mas sem incapacidade (CNPRP, 2003).

4. A responsabilidade de atribuição das pensões aos trabalhadores que sofreram um acidente de trabalho é assumida pelo FGAP - Fundo de Garantia e Actualização de Pensões por Acidente de Trabalho, substituído em 2002 pelo Fundo de Acidentes de Trabalho (FAT).

5. Na designação Outras estão incluídas as outras doenças profissionais reconhecidas que, pelo número reduzido de casos, não têm expressão estatística.

6. Sector de actividade em que a maioria das empresas se situa no norte de Portugal, região onde foi desenvolvida a investigação.

7. Versão portuguesa, adaptada por investigadores da Faculdade de Economia da Universidade de Coimbra, Centro de estudos e Investigação em Saúde, 1997, sob responsabilidade do Prof. Doutor Pedro Lopes Ferreira. 


\section{AUTORES}

\section{CARLA BARROS-DUARTE}

Universidade Fernando Pessoa, Praça 9 de Abril, nº 349, 4249-004 Porto

cbarros@ufp.pt

\section{MARIANNE LACOMBLEZ}

Universidade do Porto - Faculdade de Psicologia e de Ciências da Educação Rua Dr. Manuel Pereira da Silva4200-392 Porto

lacomb@fpce.up.pt 